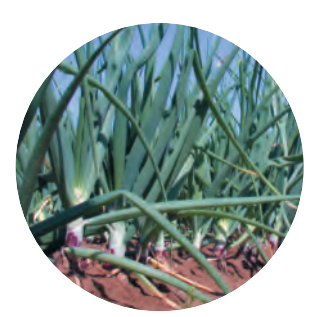
ПЕРСПЕКТИВЫ ИСПОЛЬЗОВАНИЯ
БИОПРЕПАРАТОВ В СЕЛЕКЦИИ
ЛУКОВ НА ЗЕЛЕНЬ

\title{
PERSPECTIVES OF BIOPREPARATION USE IN THE SELECTION OF ONION FOR GREENERY
}

Гинс М.С. , $^{*}$ - чл.-Корр. РАН, доктор биол. наук, зав. лаб. физиологии и биохимии растений, интродукции и функциональных продуктов https://orcid. org/0000-0001-5995-2696

Агафонов А.Ф.' - кандидат с.-Х. наук, зав. лаб. селекции и семеноводства луковыХ культур и биох Гинс В.К. - доктор биол. наук, гл.Н.С. лаб. ффизиологии и биохимии растенИй, Интродукции и фунКцИональныХ продуктов https://orcid.org/0000-0002-7053-4345

Байков А.А. ${ }^{\prime *}$ - с.н.с. лаб. физиологии и биохимии растений, ИНТрОдУКЦИи и фуНКЦЦИОНальНЫХ продУктОВ https://orcid. org/0000-0003-4393-7525 Романов В.C.' - кандидат С.-Х. наук, С.H.C. https://orcid. org/0000-0002-3287-1914

Пивоваров В.Ф. ${ }^{1}$ - научный руководитель, академик РАН, доктор с.-х. наук Гинс Е.М. ${ }^{2}$ - магистрант агробиотехнологического департамента

Федеральное государственное бюджетное научное учреждение "Федеральный научный центр овощеводства" 143072, Россия, Московская обл., Одинцовский р-н, п. ВНИИССОК, ул. СелеКционная, д. 14 "E-mail: anim@bk.ru **E-mail: physio|@inbox.n 2ФГАОУ ВО «Российский университет дружбы народов» (РУДН), 117198, Москва, ул. Миклухо-Маклая, 6

Пищевую и фармакологическую ценность в листьях лука репчатого в основном представляют аскорбиновая кислота, хлорофиллы и вторичные метаболиты: каротиноиды, соединения фенольной природы. При этом их количество зависит от условий выращивания и обработки биопрепаратами. Опыт проводили в защищенном грунте на дерново-подзолистой почве в Московской области в условиях естественной инсоляции при температуре $20 \ldots 25^{\circ} \mathrm{C}$ в марте месяце с использованием сортов лука селекции ВНИИССОК - Черный принц и Золотничок. Исследовалось влияние ростостимулирующих препаратов Альбит и Амир на содержание в листьях лука репчатого антиоксидантов и фотосинтетических пигментов. В работе показана перспективность использования ростостимулирующих растительных и бактериальных препаратов для некорневой обработки лука репчатого, позволяющих увеличить урожайность зеленых листьев и содержание антиоксидантов. В листьях лука сорта Черный принц наблюдали увеличение содержания аскорбиновой кислоты на 30\% при обработке биопрепаратом Амир, а также увеличение массы листьев на 8\% при обработке Амиром и на 14\% - при обработке биопрепаратом Альбит. Внекорневая обработка листьев лука биопрепаратами Альбит и Амир приводила также к увеличению содержания суммы спирторастворимых антиоксидантов.

Ключевые слова: лук репчатый, продуктивность, биологически активные вещества, антиоксиданты, пигменты

Для цитирования: Гинс М.С., Агафонов А.Ф., Гинс В.К., Байков А.А. Доманов В.С., Пивоваров В.Ф., ГИнс Е.М. ПЕРСПЕКТИВЬІ ИСПОЛЬЗОВАНИЯ БИОПРЕПАРАТОВ В СЕЛЕКЦИИ ЛУКОВ НА ЗЕЛЕНЬ. ОВОЩИ России. 2018;(6):70-72. DOl:10.18619/2072-9146-2018-6-70-72

сновная задача для селекционеров, работающих с луковыми культурами - создание новых сортов, которые будут иметь качественное превосходство над существующими сортами, позитивно воздействуя на здоровье населения [1]. В селекции луковых культур, предназначенных для выгонки зелени, работа заключается в создании сортов и гибридов, которые отличаются большой массой листового аппарата с высокой фотосинтетической активностью, обеспечивающей накопление большого количества сухого вещества, углеводов, минеральных элементов, и биологически активных веществ [2]. Особенно актуальны эти исследования для сортов лука, используемых в защищенном грунте [3]. Выявление биохимических маркеров сортовых отличий в линиях лука позволит проследить и описать
Gins M.S. ${ }^{2}{ }^{2 *}$ - Doctor of Science in Biology

https://orcid. org/0000-0001-5995-2696

Agafonov A.F.' - Ph.D., in Agriculture

Gins V.K.' - Doctor of Science in Biology

https://orcid. org/0000-0002-7053-4345

Baikov A.A. ${ }^{* \star}$ - senior researcher

hittps://orcid. org/0000-0003-4393-7525

Romanov V.S.' - PhD, senior researcher

https://orcid. org/0000-0002-3287-1914

Pivovarov V.F.' - Academician of RAS, Doctor of Science

in Agriculture, Professor, Laureate of State Prize, Scientific Director Gins E.M. ${ }^{2}-$ master student

FSBSI "Federal Scientific Vegetable Center"

Selectionnaya st., 14, p. VNIISSOK,

Odintsovo district, Moscow region, 143072, Russia

*E-mail: anirr@bk.ru

"**-mail: physiol@inbox.ru

FSAEl of HE "Peoples' Friendship University

of Russia" (RUDN University),

Miklukho-Maklaya st., 6, Moscow, 117198, Russia

Food and pharmacological value in onion leaves is mainly represented by ascorbic acid, chlorophylls and secondary metabolites: carotenoids, phenolic compounds. At the same time, their quantity depends on the conditions of cultivation and treatment with biostimulants. The experiment was carried out in a greenhouse on sod-podzolic soil in the Moscow region under conditions of natural insolation at a temperature of $20 \ldots 25^{\circ} \mathrm{C}$ in March using varieties of VNIISSOK selection - Chernyj princ and Zolotnichok. The effect of Albit and Amir biostimulants on the content of antioxidants and photosynthetic pigments in the leaves of onion was studied. The work shows the promise of using growth-stimulating plant and bacterial preparations for foliar treatment of onion leaves, which allow increasing the yield of leaves and the content of antioxidants. In the leaves of the Chernyj princ variety, an increase in the content of ascorbic acid by $30 \%$ was observed when treated with biostimulant Amir, as well as an increase in leaf weight by $8 \%$ when treated with Amir and by $14 \%$ when treated with biostimulant Albit. Foliar treatment of onion leaves with biostimulants Albit and Amir resulted in an increase in the amount of ethanol-soluble antioxidants.

Keywords: Allium cepa, productivity, biologically active substances, antioxidants, pigments

For citation: Gins M.S., Agafonov A.F., Gins V.K., Baikov A.A., Romanov V.S Pivovarov V.F., Gins E.M. PERSPECTIVES OF BIOPREPARATION USE IN THE SELECTION "OF ONION FOR GREENERY. Vegetable crops of Russia. 2018;(6):70-72. (In Russ.) DOl:10.18619/2072-9146-2018-6-70-72

те изменения в их содержании, которые лежат в основе ответной реакции генома растения на действия позитивных и отрицательных факторов внешней среды.

Целью настоящей работы является изучение содержания антиоксидантов и фотосинтетических пигментов в листьях лука репчатого, обработанных ростостимулирующими препаратами Альбит и Амир.

\section{Материалы и методы}

Объектом исследования служили листья лука репчатого сортов селекции ВНИИССОК - Черный принц и Золотничок. Растения выращивали в Подмосковье в защищенном грунте при естественном освещении в марте месяце при температуре 
20...25ㄷ. В опытах использовали все листья с луковицы.

Для некорневой обработки листьев лука использовали коммерческий препарат Альбит, разработанный на основе почвенных бактерий Baccilus megaterium, индуцирующий защитные свойства по отношению к фитопатогенам и повышающий урожайность сельскохозяйственных культур [2, 4], и биопрепарат Амир, созданный на основе растительного сырья из растения амарант (Amaranthus tricolor L.) сорта Валентина.

Определение суммарного содержания антиоксидантов в водных $\left(\mathrm{AO} \mathrm{H}_{2} \mathrm{O}\right)$ и этанольных экстрактах $\left(\mathrm{AO} \mathrm{C}_{2} \mathrm{H}_{5} \mathrm{OH}\right)$ производили амперометрическим методом с использованием галловой кислоты (ГК) в качестве стандарта [5]. Определение содержания фотосинтетических пигментов и содержание аскорбиновой кислоты проводили как описано в работе [6]. Растения обрабатывали биопрепаратами один раз за неделю до срезки. Опрыскивали в концентрации Альбит - $10^{-5}$ объемных \% и Амир - $10^{-5}$ объемных \%. В таблицах приведены средние арифметические значения и их стандартные отклонения.

Результаты и их обсуждение

Листья лука репчатого сорта Черный принц отличаются высоким содержанием аскорбиновой кислоты - от 60 до 80 мг\% при выращивании в открытом грунте в летний период [7], тогда как в зелени лука Черный принц и Золотничок, выращенных в марте в защищенном грунте было обнаружено меньшее количество витамина С (табл. 1). Известно, что количество аскорбиновой кислоты в листьях лука в ранневесенний период можно повысить путем обработки луковиц ростостимулирующими биологически активными препаратами, хотя их действие на разные сорта лука неоднозначно. Ранее нами было обнаружено позитивное влияние на содержание витамина С в листьях лука репчатого сорта Штутгартер Ризен при предпосевной обработке луковиц биопрепаратом Альбит и селенатом натрия, в то время как в листьях сортов лука Одинцовец, Мячковский 300 и Бессоновский местный наблюдали некоторое уменьшение количества витамина С [1]. В нашем опыте действие препарата Альбит на содержание аскорбиновой кислоты и сухого вещества в листьях было неоднозначным. Для сорта Черный принц можно отметить некоторую тенденцию к росту, однако достоверно от контроля не отличающуюся. Сорт Золотничок оказался еще менее чувствительным к воздействию препарата Альбит

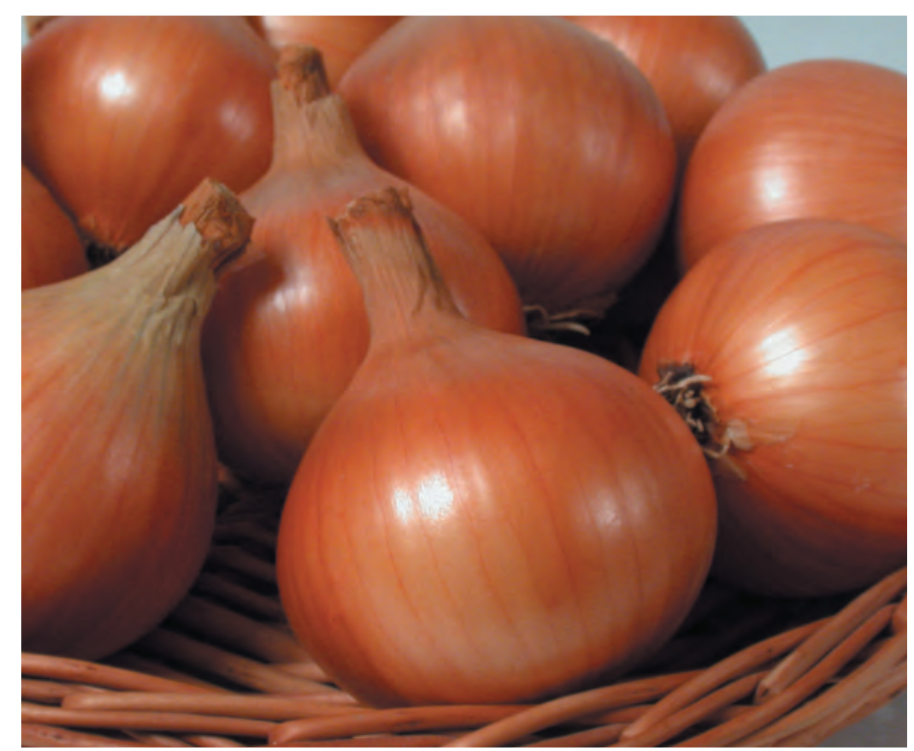

Лук репчатый Золотничок.

Variety of onion 'Zolotnychok'.

ство в данном случае результат был сравним с контролем, но имелась тенденция к росту.

Масса листьев лука репчатого сорта Черный принц при обработке листьев биопрепаратом Альбит увеличилась на 14\%, Амир - на 8\%. У сорта Золотничок увеличение массы листьев было незначительным по сравнению с контролем.

Основными фотоактивными компонентами листьев лука являются хлорофиллы и сопутствующие им каротиноиды, которые, в том числе, определяют эффективность фотосинтеза. При некорневой обработке листьев лука сорта Черный принц биопрепаратом Альбит наблюдали увеличение суммы хлорофиллов и тенденцию к уменьшению количества каротиноидов. Амир приводил к снижению обоих показателей. В то время как в листьях растений сорта Золотничок, обработанных биопрепаратом Альбит, происходило достоверное снижение суммы хло-

Таблица 1. Содержание аскорбиновой кислоты (мг\%) в листьях растений лука, обработанных ростстимулирующими препаратами Альбит и Амир

Table 1. The content of ascorbic acid $(\mathrm{mg} \%)$ in the leaves of onion plants treated with biostimulants Albit and Amir

\begin{tabular}{|l|c|c|c|}
\hline Сорт & Контроль & Альбит & Амир \\
\hline Черный принц & $30 \pm 2$ & $32 \pm 2$ & $39 \pm 2$ \\
\hline Золотничок & $23 \pm 2$ & $22 \pm 2$ & $25 \pm 2$ \\
\hline
\end{tabular}

по указанным выше параметрам (табл. 1-2). При обработке биопрепаратом Амир наблюдали достоверное увеличение содержания аскорбиновой кислоты на 30\% по сравнению с контролем в листьях сорта Черный принц, в листьях сорта Золотничок имелась лишь тенденция к росту. По показателю сухое веще- рофиллов, а снижение суммы каротиноидов было на уровне тенденции. Обработка препаратом Амир давала результаты, сравнимые с контролем (табл. 3).

Суммарное содержание антиоксидантов в водном экстракте листьев лука сорта Черный принц снизилось при действии обоих биопрепаратов, а у сорта Золотничок при действии Амира

Таблица 1. Содержание аскорбиновой кислоты (мг\%) в листьях растений лука, обработанных ростстимулирующими препаратами Альбит и Амир

Table 1. The content of ascorbic acid $(\mathrm{mg} \%)$ in the leaves of onion plants treated with biostimulants Albit and Amir

\begin{tabular}{|c|c|c|c|}
\hline Сорт & Контроль & Альбит & Амир \\
\hline Черный принц & $7,5 \pm 0,5$ & $8,0 \pm 0,5$ & $8,0 \pm 0,5$ \\
\hline Золотничок & $6,3 \pm 0,4$ & $6,4 \pm 0,4$ & $6,5 \pm 0,4$ \\
\hline
\end{tabular}


Таблица 3. Суммарное содержание хлорофилла $(a+b)$, каротиноидов и низкомолекулярных антиоксидантов в листьях лука репчатого сорта Золотничок и Черный принц, обработанных биопрепаратами Table 3. The total content of chlorophyll $(a+b)$, carotenoids and low-molecular antioxidants in the onion leaves of the Zolotnichok and Chernyj prints varieties treated with biostimulants

\begin{tabular}{|c|c|c|c|c|}
\hline \multirow{2}{*}{ Образец } & Хлорофилл & Каротиноиды & $\mathrm{AO} \mathrm{H} 2 \mathrm{O}$ & $\mathrm{AO} \mathrm{C} 2 \mathrm{H} 5 \mathrm{OH}$ \\
\hline & \multicolumn{2}{|c|}{$\mathrm{Mr} / \mathrm{r}$} & \multicolumn{2}{|c|}{ мг-экв ГK/г } \\
\hline \multicolumn{5}{|c|}{ Черный принц } \\
\hline Контроль & $0,73 \pm 0,04$ & $0,24 \pm 0,01$ & $0,31 \pm 0,02$ & $0,39 \pm 0,02$ \\
\hline Амир & $0,62 \pm 0,03$ & $0,21 \pm 0,01$ & $0,27 \pm 0,01$ & $0,44 \pm 0,02$ \\
\hline Альбит & $0,90 \pm 0,05$ & $0,23 \pm 0,01$ & $0,28 \pm 0,01$ & $0,43 \pm 0,02$ \\
\hline \multicolumn{5}{|c|}{ Золотничок } \\
\hline Контроль & $0,84 \pm 0,04$ & $0,27 \pm 0,01$ & $0,25 \pm 0,01$ & $0,39 \pm 0,02$ \\
\hline Амир & $0,82 \pm 0,04$ & $0,28 \pm 0,01$ & $0,28 \pm 0,01$ & $0,44 \pm 0,02$ \\
\hline Альбит & $0,75 \pm 0,04$ & $0,25 \pm 0,01$ & $0,24 \pm 0,01$ & $0,41 \pm 0,02$ \\
\hline
\end{tabular}

уровень антиоксидантов повысился (табл. 3). В этанольных экстрактах, полученных из листьев изученных сортов, наблюдали возрастание содержания антиоксидантов при некорневой обработке листьев лука биопрепаратами Альбит и Амир.

\section{Заключение}

Были выявлены сортовые различия по способности листьев лука накапливать биологически активные вещества и фотосинтетические пигменты, установлена отзывчивость сортов на воздействие препаратов Альбит и Амир. Внесен вклад в разработку новых технологических приемов возделывания лука репчатого на выгонку в защищенном грунте, включающий использование экологически безопасных регуляторов, влияющих на качество листьев, что позволяет увеличить листовую массу лука и ее питательную ценность.

Работа выполнена при частичной поддержке "Проекта-победителя" Грантового конкурса Стипендиальной программы Владимира Потанина 2016/2017 (договор о гранте № ГПК-19/17 от 05.06.2017 г.)

\section{- Литература}

1. Кононков П.Ф., Камалеев Х.Б., Гинс М.С. Перспективные элементы технологии выращивания зелени лука репчатого для функционального питания// Всероссийский науч.-исслед. ин-т селекции и семеноводства овощных культур. Москва, 2006.

2. Гинс М.С., Гинс В.К., Байков А.А., Злотников А.К., Агафонов А.А., Логунова В.В. Влияние Альбита на продуктивность и пищевую ценность различных сортов лука // Защита и карантин растений. 2017. № 9. С.22-23.

3. Гинс М.С., Камалеев Х.Б., Суслова Л.В., Кононков П.Ф., Агафонов А.Ф., Злотников А.К. Влияние ростстимулирующего препарата Альбит на морфометрические показатели лука репчатого // Гавриш. 2004. № 5. С.23-34.

4. Gins M.S., Gins V.K., Baikov A.A. et al. Antioxidant content and growth at the initial ontogenesis stages of Passiflora incarnata plants under the influence of biostimulant Albit // Russ. Agricult. Sci. (2017) 43: 384. https://doi.org/10.3103/S1068367417050068

5. Гинс М.С., Гинс В.К., Байков А.А., Романова Е.В., Кононков П.Ф., Торрес М.К., Лапо О.А. Методика анализа суммарного содержания антиоксидантов в листовых и листостебельных овощных культурах // Учебно-методическое пособие. Москва, 2013.

6. Гинс М.С., Гинс В.К. Физиолого-биохимические основы интродукции и селекции овощных культур. Москва, 2011.

7. Гинс М.С., Пивоваров В.Ф., Гинс В.К., Кононков П.Ф., Дерканосова Н.М. ПРИ СОЗ ДАНИИ ФУНКЦИОНАЛЬНЫХ ПРОДУКТОВ НА ОСНОВЕ ОВОЩНЫХ КУЛЬТУР. ОВОЩИ России. 2014;(1):4-9. https://doi.org/10.18619/2072-9146-2014-1-4-9

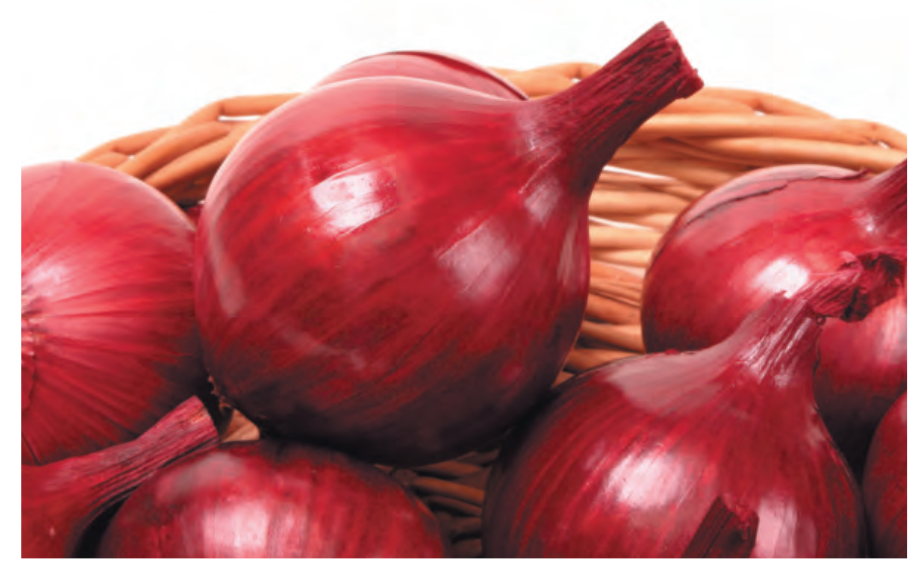

Лук репчатый Черный принц. Variety of onion 'Chemiy prints'.

- References

1. Kononkov P.F., Kamaleev Kh.B., Gins M.S. Promising elements of the technology of growing greens of bulb onions for functional nutrition. All-Russian Research Institute of Vegetable Breeding and Seed Production. Moscow, 2006.

2. Gins M.S., Gins V.K., Baikov A.A., Zlotnikov A.K., AgafonovA.A., Logunova V.V. The influence of Albit on the productivity and nutritional value of different varieties of onions // Protection and quarantine of plants. 2017. No.9. P.22-23

3. Gins, M.S., Kamaleev, Kh.B., Suslova, L.V., Kononkov, P.F., Agafonov, A.F., Zlotnikov, A.K. The influence biostimulant Albit on the morphometric parameters of onion // Gavrish. 2004. No.5. P.2334

4. Gins M.S., Gins V.K., Baikov A.A. et al. Antioxidant content and growth at the initial ontogenesis stages of Passiflora incarnata plants under the influence of biostimulant Albit // Russ. Agricult. Sci. (2017) 43: 384. https://doi.org/10.3103/S1068367417050068

5. Gins M.S., Gins V.K., Baikov A.A., Romanova E.V., Kononkov P.F., Torres M.K., Lapo O.A. Methods of analysis of the total antioxidant content in leafy vegetable crops // Teaching guide. Moscow, 2013. 6. Gins, M.S., Gins, V.K. Physiological and biochemical basis for the introduction and selection of vegetable crops. Moscow, 2011.

7. Gins M.S., Pivovarov V.F., Gins V.K., Kononkov P.F., Derkanosova N.M. SCIENCE SERVICE OF INNOVATIVE TECHNOLOGIES FOR DEVELOPMENT OF FUNCTIONAL FOOD FROM VEGETABLE CROPS. Vegetable crops of Russia. 2014;(1):4-9. (In Russ.) https://doi.org/10.18619/2072-91462014-1-4-9 